\title{
La BIODIVERSIDAD en la RED
}

\section{Santiago B ordera Sanjuán}

CIBIO

El tráfico internacional de especies de fauna y flora silvestres mueveanualmente miles de millones de dólares en todo el mundo. Este comercio desmesurado conlleva en no pocos casos la drástica disminución, o incluso la total extinción, de muchas de estas especies, lo que supone pérdidas irreparables en la biodiversidad de amplias zonas del planeta. Precisamente con el fin de paliar este problema entró en vigor en 1975 el conocido CITES (Convención sobre el Comercio Internacional de Especies Amenazadas de Fauna y Flora Silvestres) cuyo objetivo básico es el de proteger a las especies silvestres de una explotación desmedida e impedir el comercio de aquellas que se encuentren en peligro de extinción. EI CITES cuenta actualmentecon 150 países miembros y sus principiosemanan del documento sobre las estrategias para el futuro de la vida, publicado conjuntamente por laUICN - Unión M undial para la N aturaleza, el PN U M A - Programa de las $\mathrm{N}$ aciones Unidas para el M edio Ambiente y el W W F - Fondo M undial para la $\mathrm{N}$ aturaleza.

En relación con esta problemática apuntamosen este número algunas direcciones que pueden facilitarnos amplia y completa información sobre esta convención y otros temas relacionados con la amenaza de especies silvestres.

http://www.wcmc.org.uk/C IT ES/esp/index.shtml

Página principal deCITES en castellano queofrece extensa información sobre su constitución, fines y partes que han ratificado su adhesión. D el mismo modo se puede acceder al texto integro de la convención y a un gran número de resoluciones y decisiones, comités y grupos de trabajo, programas en desarrollo, eventos futuros, bases de datos de las especies de flora y fauna incluidas en el convenio e información variada sobre tratados medioam- bientales, O N Gs asociadas y publicaciones. Todo sobre CITES.

\section{http://www.iucn.org/}

Página de la U nión M undial para la N aturaleza que ofrece información sobre la organización, los fines, miembros, comisiones de trabajo, acontecimientos y publicaciones entre otros aspectos. También se puede acceder a los distintos programas desarrollados por las diferentes comisiones, siendo destacables los apartados dedicados a los espacios naturales y las especies.

\section{http://www.wcmc.org.uk/data/database/rl anml combo.html}

http://www.wcmc. org.uk/species/plants/plants-bytaxon.htm

Interesantes páginas del «World Conservation $M$ onitoring Centre» que proporcionan acceso directo a dos bases de datos que contienen respectivamente las listas rojas de la UICN de especies de animales y plantas amenazadas del mundo. En cada base se entra por categorías taxonómicas o por el nombre común y posteriormente se puede concre tar el país y la categoría del grado de amenaza. Existen documentos adicionales sobre las diferentes categorías utilizadas, estadísticas, bibliografía y notas aclaratorias. Unas páginas de gran utilidad.

\section{http:// www.endangeredspecie.com/}

O frece diversos apartados de carácter divulgativo con información sobre causas de amenaza en las especies, qué hacer y cómo ayudar a su conservación, leyes de protección, organizaciones, bibliografía y diversos aspectos de carácter educativo. 